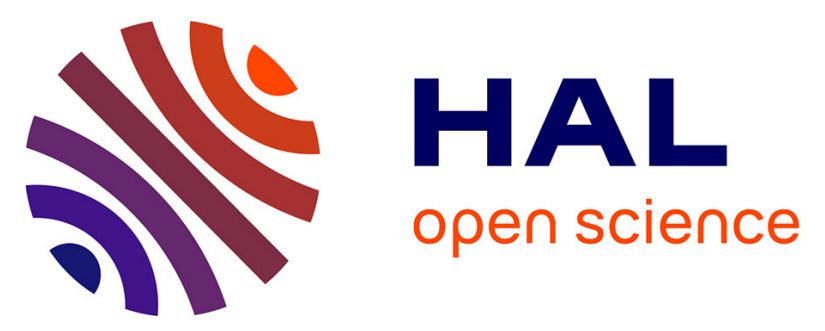

\title{
Diagnostic utility of mammaglobin and GCDFP-15 in the identification of primary neuroendocrine carcinomas of the breast
}

Eugeni Lopez-Bonet, Maria Carmen Pérez-Martínez, Begoña Martin-Castillo, Miguel Alonso-Ruano, Francesc Tuca, Cristina Oliveras-Ferraros, Sílvia Cufí, Alejandro Vazquez-Martin, Miquel Beltràn, Luis Bernadó, et al.

\section{To cite this version:}

Eugeni Lopez-Bonet, Maria Carmen Pérez-Martínez, Begoña Martin-Castillo, Miguel Alonso-Ruano, Francesc Tuca, et al.. Diagnostic utility of mammaglobin and GCDFP-15 in the identification of primary neuroendocrine carcinomas of the breast. Breast Cancer Research and Treatment, 2010, 126 (1), pp.241-245. 10.1007/s10549-010-1229-9 . hal-00589446

\section{HAL Id: hal-00589446 https://hal.science/hal-00589446}

Submitted on 29 Apr 2011

HAL is a multi-disciplinary open access archive for the deposit and dissemination of scientific research documents, whether they are published or not. The documents may come from teaching and research institutions in France or abroad, or from public or private research centers.
L'archive ouverte pluridisciplinaire HAL, est destinée au dépôt et à la diffusion de documents scientifiques de niveau recherche, publiés ou non, émanant des établissements d'enseignement et de recherche français ou étrangers, des laboratoires publics ou privés. 


\title{
Diagnostic utility of mammaglobin and GCDFP-15 in the identification of primary neuroendocrine carcinomas of the breast
}

\author{
Eugeni Lopez-Bonet ${ }^{1,2,3}$ \\ Maria Carmen Pérez-Martínez 1,3 \\ Begoña Martin-Castillo 3,4 \\ Miguel Alonso-Ruano 3,5 \\ Francesc Tuca 3,5 \\ Cristina Oliveras-Ferraros 3,6 \\ Sílvia Cufí 3,6 \\ Alejandro Vazquez-Martin 3,6 \\ Miquel Beltràn 3,7 \\ Luis Bernadó ${ }^{1,3}$ \\ Javier A. Menendez 3,6
}

1 Department of Anatomical Pathology, Dr. Josep Trueta University Hospital

2 Department of Pathology, Autonomous University of Barcelona School of Medicine (UAB)

3 Girona Biomedical Research Institute (IdIBGi)

4 Unit of Clinical Research, Catalan Institute of Oncology-Girona (ICO-Girona)

5 Department of Gynaecology, Dr. Josep Trueta University Hospital

6 Unit of Translational Research, Catalan Institute of Oncology-Girona (ICO-Girona)

7 Medical Oncology, Catalan Institute of Oncology-Girona (ICO-Girona)

1,3,4,5,6,7 Avenida de Francia s/n, E-17007 Girona, Catalonia (SPAIN)

2 Campus de la UAB, Bellaterra, E-08193 Barcelona, Catalonia (SPAIN)

*Address for correspondence:

JAVIER A. MENENDEZ, Ph.D.

Catalan Institute of Oncology, Girona (ICO-Girona)

Dr. Josep Trueta University Hospital

Avenida de França s/n, E-17007 Girona, Catalonia (SPAIN)

Phone: + 34-972-225-834 Ext. 2553

Fax: + 34-972-217-344

E-mail: jmenendez@iconcologia.net; imenendez@idibgi.org

Running title: Mammaglobin \& GCDFP-15 in neuroendocrine breast cancer Key words: Neuroendocrine tumors; Mammaglobin; GCDFP-15; breast cancer 
In addition to the presence of morphological neuroendocrine (NE) features, expression of the NE markers chromogranin A and synaptophysin has been considered the most sensitive and specific immunohistochemical feature in the diagnosis of pure, solid NE breast carcinomas [NEBC; 1]. Following these criteria, the existence of NEBC can be accurately confirmed in $<2 \%$ of all primary breast cancers when using adequate cytological specimens including fine needle aspiration smears [1-4]. Within a working model for a breast cancer molecular taxonomy [5], recent gene expression profiling studies have confirmed a distinct nature of NEBC from conventional invasive ductal carcinomas as well as their belonging to the goodprognosis (being positive for hormone receptors and HER2-negative) subgroup of luminal A breast tumors [6]. NEBC may occur, however, as a first presentation of an occult metastatic non-mammary neuroendocrine tumor or as a bona fide primary breast tumor. Therefore, the clinical effect of the occurrence of neuroendocrine differentiation in breast cancer should be carefully examined to reduce or avoid the risk of a misdiagnosis or under-diagnosis. In this regard, Richter-Ehrenstein et al. have recently evaluated a new diagnostic tool to distinguish between primary NEBC from a metastatic disease of other sites [7]. Using the immunohistochemical markers for epithelial of breast origin mammaglobin and Gross Cystic Disease Fluid Protein (GCDFP-15), they compared a subset of pure $\operatorname{NEBC~(~} n=9)$ with a cohort of nonmammary neuroendocrine tumors. In their hands, mammaglobin was positive in 4 out of 9 tumors while GCDFP-15 was expressed in 6 out of 9 cases. In three patients, both markers were negative. Remarkably, they did not find any expression of mammaglobin or GCFFP-15 in immunohistochemical evaluation of chromogranin A/synaptophysin-positive non-mammary neuroendocrine tumors [7].

We have recently determined the incidence, clinico-pathological features and immunohistochemical profiling of primary pure NEBC in a large series of infiltrating breast tumors collected from 1989 to 2010 in our institution (Dr. Josep Trueta University Hospital, Girona, Catalonia). From the entire series of more than 1500 carcinomas, only 8 cases fully satisfied the primary pure NEBC criteria by the WHO (i.e. the presence of $>50 \%$ tumor immunoreactivity for one of neuroendocrine markers including chromogranin, synaptophysin and CD56), which constitutes an incidence of solid NEBC as low as $0.5 \%$ [data updated from ref. 8]. To definitely confirm the primary nature of these endocrine tumors, we recently tested the 
hypothesis that mammaglobin stating can help, in combination with GCDFP-15 (a sensitive and specific marker of breast carcinoma), to establish the correct diagnosis of breast carcinomas [9]. Table 1 summarizes the immunohistochemical profile for the expression of estrogen receptor (ER), progesterone receptor (PR), HER2, mammaglobin, and GCDFP-15 in tumor specimens from NEBC patients. Our findings largely recapitulate those presented by Richter-Ehrenstein et al [7]. All NEBC expressed high levels of estrogen and progesterone receptors. Mammaglobin was positive in 4 out of 9 samples. In contrast, GCDFP-15 was expressed in 7 out of 9 specimens. We did not observe discordant expression of mammaglobin and GCDFP15 markers between primary and metastatic tissues in a patient that debuted with metastasis in the soft tissue of the check prior to diagnosis of primary NEBC. It was intriguing that HER2 2+ staining (but absence of gene amplification) was found in the sole NEBC that was negative for both markers. Richter-Ehrenstein et al similarly reported that HER2 overexpression was found in only one NEBC, which was negative for both markers [7]. Although the very small number of cases obviously limits the relevance of the correlation between HER2 positivity and mammaglobin/GCDFP-15 double-negative NEBC patients, additional studies with longer follow-up and more cases need to be further pursued to establish whether this "combimarker" (i.e. detecting HER2 overexpression in the absence of mammaglobin/GCDFP-15 markers) may delineate a distinctive subgroup of luminal B-like (i.e. ER-positive or PR-positive and HER2-positive [10]) among the well-established ER/PR-positive HER2-negative status of NEBC. Although GCDFP-15 has classically been considered a secretary marker of apocrine differentiation in breast cancer $[11,12]$, the fact that the GCDFP15 positivity is transient (i.e. breast cancer cases which have apocrine features but lack GCDFP-15 expression suggest advanced apocrine carcinomas [13]) together with the pre-clinical finding that the prolactin-inducible protein $P I P / G C D F P-15$ gene was the mostly up-regulated mRNA in luminal B (ER-positive/HER2-positive) BT-474 breast cancer cells treated with the insulin-like growth factor-I receptor (IGF-IR) antagonist NVP-AEW541 and the anti-HER2 monoclonal antibody trastuzumab [13], reinforce the suggestion that yet to be established regulatory relationship between GCDFP-15, HER2, and apocrine differentiation would take place in subsets of NEBC $[14,15]$. 
In summary, our findings strongly support Richter-Ehrenstein's conclusion that mammaglobin and GCDFP-15 as markers of epithelial breast origin may efficiently work as a new reliable diagnostic tool to distinguish endocrine tumors of the breast from a metastatic non-mammary neuroendocrine disease. Given that the diagnosis of NEBC cases has been made mostly following surgical intervention including mastectomy and that most studies have confirmed that NEBC show a less aggressive clinical behavior when compared with unselected breast cancers, these findings strongly suggest that when suspecting neuroendocrine differentiation, preoperative pathological diagnosis by core biopsies can be employed to immunohistochemically establish the primary nature of mammary NEBC to guide in their conservative medical and surgical management. Further research effort using large clinically annotated series of breast tumors.is warranted to definitely establish whether NEBC defined by two- (chromogranin A and synaptophysin) or five (chromogranin A, synaptophysin, HER2, mammaglobin and GCDFP-15)-biomarker surrogate panels might explain a recent suggestion of invasive NEBC as a distinctive subtype of biologically aggressive breast cancer[17]

Acknowledgements: This work was supported in part by the Xarxa de Banc de Tumors de Catalunya (XBTC) sponsored by the Pla Director d'Oncologia de Catalunya. Alejandro Vazquez-Martin is the recipient of a "Sara Borrell" post-doctoral contract (CDo8/o0283, Ministerio de Sanidad y Consumo, Fondo de Investigación Sanitaria -FIS-, Spain). Work at Menendez' laboratory is supported in part by the Instituto de Salud Carlos III (Ministerio de Sanidad y Consumo, Fondo de Investigación Sanitaria -FIS-, Spain, Grants CPo5-00090 and PIo6-0778 and RDo60020-0028), the Fundación Científica de la Asociación Española Contra el Cáncer (AECC, Spain), and by the Ministerio de Ciencia e Innovación (SAF2009-11579, Plan Nacional de I+D+ I, MICINN, Spain). 


\section{REFERENCES}

1. WHO (2003): In: Tavassoli FA, Devilee P (eds) World Health Organization classification of tumors. Pathology and genetics of tumours of the breast and female genital organs. IARC Press, Lyib, pp 9-112.

2. Günhan-Bilgen I, Zekioglu O, Ustün EE, Memis A, Erhan Y (2003) Neuroendocrine differentiated breast carcinoma: imaging features correlated with clinical and histopathological findings. Eur Radiol 13:788-793.

3. Kawasaki T, Nakamura S, Sakamoto G et al (2010) Neuroendocrine ductal carcinoma in situ of the breast: cytological features in 32 cases. Cytopathology. 2010 Mar 5. [Epub ahead of print]

4. Righi L, Sapino A, Marchiò C, Papotti M, Bussolati G (2010) Neuroendocrine differentiation in breast cancer: established facts and unresolved problems. Semin Diagn Pathol 27:69-76.

5. Perou CM, Sorlie T, Eisen MB et al (2000) Molecular portraits of human breast tumours. Nature 406: 747-752.

6. Weigelt B, Geyer FC, Horlings HM, et al (2009) Mucinous and neuroendocrine breast carcinomas are transcriptionally distinct from invasive ductal carcinomas of no special type. Mod Pathol 22:1401-1414.

7. Richter-Ehrenstein C, Arndt J, Buckendahl AC et al (2010) Solid neuroendocrine carcinomas of the breast: metastases or primary tumors? Breast Cancer Res Treat. 2010 Sep 25. [Epub ahead of print]

8. Lopez-Bonet E, Alonso-Ruano M, Barraza G et al (2008) Solid neuroendocrine breast carcinomas: incidence, clinico-pathological features and immunohistochemical profiling. Oncol Rep 20:1369-1374.

9. Bhargava R, Beriwal S, Dabbs DJ (2007) Mammaglobin vs GCDFP-15: an immunohistologic validation survey for sensitivity and specificity. Am J Clin Pathol 27:103-113.

10. Carey LA, Perou CM, Livasy CA et al (2006) Race, breast cancer subtypes, and survival in the Carolina Breast Cancer Study. JAMA 295:2492-2502.

11. Caputo E, Manco G, Mandrich L, Guardiola J (2000) A novel aspartyl proteinase from apocrine epithelia and breast tumors. J Biol Chem 275:7935-7941.

12. Sapino A, Righi L, Cassoni P et al (2001) Expression of apocrine differentiation markers in neuroendocrine breast carcinomas of aged women. Mod Pathol. 2001 A14:768-776.

13. Honma N, Takubo K, Akiyama F et al (2005) Expression of GCDFP-15 and AR decreases in larger or node-positive apocrine carcinomas of the breast. Histopathology 47:195-201.

14. Esparís-Ogando A, Ocaña A, Rodríguez-Barrueco R et al (2008). Synergic antitumoral effect of an IGF-IR inhibitor and trastuzumab on HER2-overexpressing breast cancer cells. Ann Oncol 19:1860-1869.

15. Bhargava R, Beriwal S, Striebel JM, Dabbs DJ (2010) Breast cancer molecular class ERBB2: preponderance of tumors with apocrine differentiation and expression of basal phenotype markers $\mathrm{CK}_{5}, \mathrm{CK}_{5} / 6$, and EGFR. Appl Immunohistochem Mol Morphol 18:113-118.

16. Vranic S, Tawfik O, Palazzo J et al (2010) EGFR and HER-2/neu expression in invasive apocrine carcinoma of the breast. Mod Pathol 23:644-653.

17. Wei B, Ding T, Xing Y et al (2010). Invasive neuroendocrine carcinoma of the breast: a distinctive subtype of aggressive mammary carcinoma. Cancer 116:44634473. 


\section{FIGURE LEGEND}

Figure 1. Immunohistochemical staining of different NEBC tissues for mammaglobin and GCDFP-15. Representative slides of primary (and metastatic) lesions of solid NEBC including surgical specimens and trucut core biopsies were analyzed for mammaglobin (FLEX Monoclonal Mouse Anti-Human Mammaglobin Clone 304-1A5, Ready-to-Use [Link]. DAKO. Code IRo74) and GCDFP-15 FLEX Monoclonal Mouse Anti-Human Gross Cystic Disease Fluid Protein-15 Clone 23A3 Ready-to-Use [Link]. DAKO. Code IR077) using standardized immunohistochemical techniques and robotic autostainers (Dako Autostainer Plus system; DAKO, DakoCytomation, Inc. Glostrup, Denmark). Binding results were visualized with the Envision ${ }^{\circledR}$ System (DakoCytomation, Inc.), which uses horseradish peroxidase-labelled polymer that is conjugated with secondary antibodies. 3,3-diaminobenzidine tetrahydrochloride (DAB) was used for the visualization of the antibody/enzyme complex. Slides were counterstained for nuclei with Meyer's hematoxylin and examined by light microscopy. Tumor immunoreactivity (negative, weak positive, moderate/strong positive) was scored in combination with the percent of cells showing positive staining. Figure shows typical examples of negative (Neg) or positive (Pos) strong staining of some tumor cells for mammaglobin $(A, B, C)$ and moderate to strong cytoplasmic expression for GCDFP-15 $(D, E, F)$ 


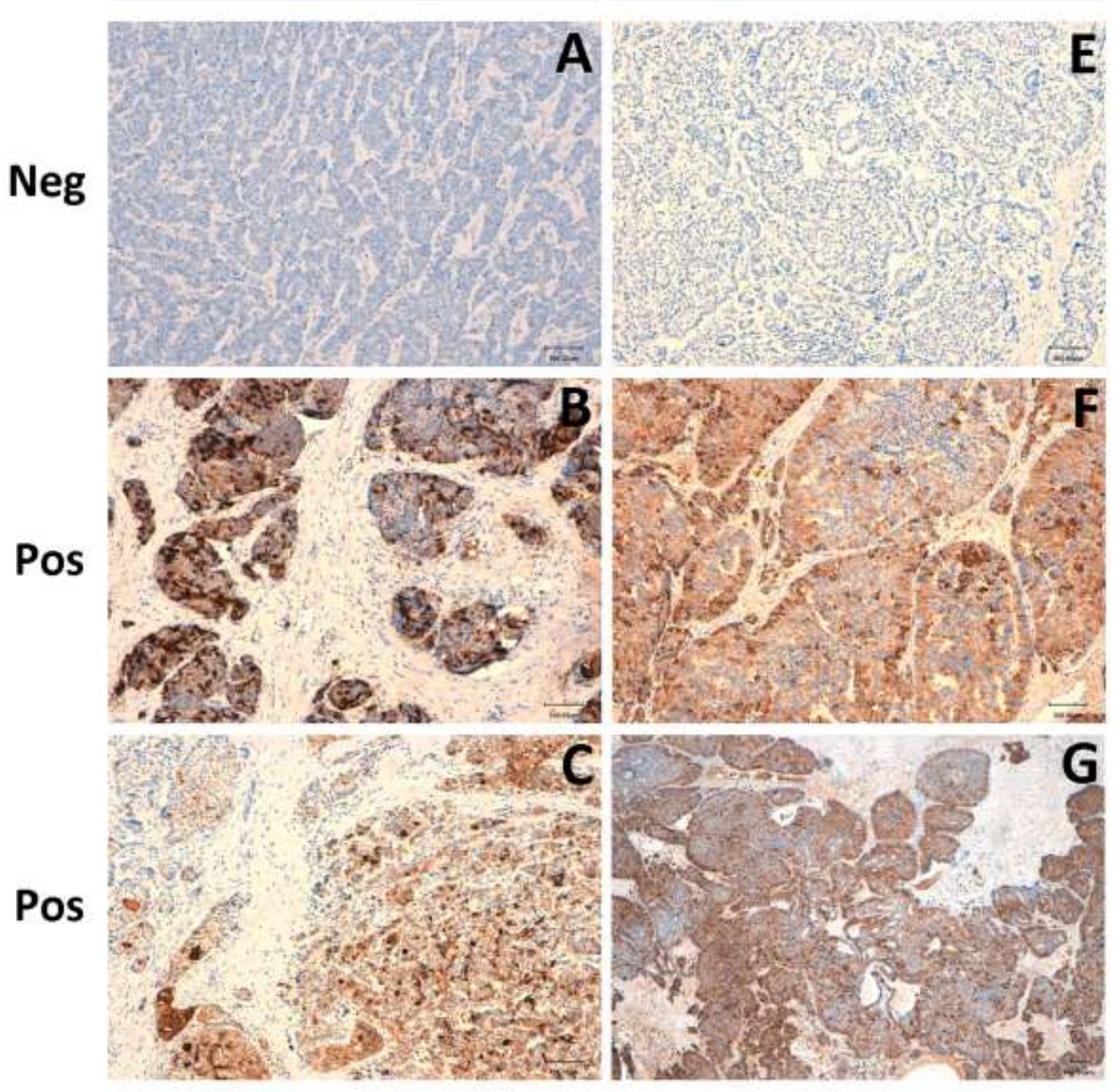


Table 1. Immunohistochemical expression profiles of primary pure neuroendocrine breast carcinomas

Patient Estrogen Progesterone HER2 Mammaglobin GCDFP-

Number Receptor Receptor

\begin{tabular}{|c|c|c|c|c|c|}
\hline 1 & Positive & Positive & - & Positive & Positive \\
\hline 2 & Positive & Positive & - & Negative & Positive \\
\hline 3 & Positive & Positive & - & Positive & Positive \\
\hline 4 & Positive & Positive & - & Negative & Positive \\
\hline 5 & Positive & Positive & - & Positive & Positive \\
\hline $6 \mathrm{M}^{\mathrm{a}}$ & Positive & Positive & - & Negative & Positive \\
\hline $6 \mathrm{P}^{\mathrm{b}}$ & Positive & Positive & - & Negative & Positive \\
\hline 7 & Positive & Positive & $\begin{array}{c}2+ \\
\left(\text { HercepTest }^{\top M}\right) \mathrm{c}\end{array}$ & Negative & Negative \\
\hline 8 & Positive & Positive & - & Positive & Negative \\
\hline
\end{tabular}


a This woman debuted with metastasis in the soft tissue of the check (6M)

b Extensive staging revealed a primary neuroendocrine breast carcinoma (6P)

c HER2 immunohistochemistry was performed using a Dako HercepTest (Dako) kit according to the designated procedure 